\title{
Research on Teaching Reform of Stamping Process and Die Design
}

\author{
Zengsheng Wang \\ School of Mechanical Engineering \\ Huanghe Science and Technology College \\ Zhengzhou, China 450063
}

\author{
Hansong Yang \\ School of Mechanical Engineering \\ Huanghe Science and Technology College \\ Zhengzhou, China 450063
}

\author{
Guohua $\mathrm{Mu}$ \\ School of Mechanical Engineering \\ Huanghe Science and Technology College \\ Zhengzhou, China 450063
}

\begin{abstract}
With characteristics of the course "Stamping Process and Die Design" and problems existing in teaching using traditional method, reform measures taken by some colleges are discussed in this paper, including teaching content, teaching material, teaching mode, teaching method, teaching resources and information-based teaching. As indicated in the research, the method of project-oriented teaching is the tendency of teaching reform, and the most effective teaching mode.
\end{abstract}

Keywords -stamping process and die design; teaching reform; project-oriented teaching

\section{INTRODUCTION}

The course of "Stamping process and die design" is an important professional course majoring material forming and control engineering, and mechanical engineering and automation, also is a core course of majoring die design. The course mainly teaches the basic principle and process of stamping, and structure and design method of stamping die, relating to many areas of knowledge of mechanical drawing, mechanical engineering, mechanics, engineering material and heat treatment. With the characteristics of wide knowledge, practical, complex and poor-logic, it is difficult to teach and learn this course using traditional teaching method, and adapt to the requirements of training applied talents. In recent years, some remarkable results have been achieved by many colleges through continuous exploration, reform, and mainly included following aspects:

\section{OPTIMIZING AND DESIGN OF TEACHING CONTENT}

In order to meet the requirements of high-quality applied talents combined with the nature and characteristics of the course, two objectives of "knowledge plus capacity" and three levels of "theory teaching plus case teaching plus extracurricular self-learning" are applied in teaching design in Anhui Engineering University.

Hereinto, the objective of "knowledge" refers to the

Project Resource: (High education NO.964 in 2012), Practice Base of National College Student (High education NO.48 in 2013), Henan Province Ordinary University Undergraduate Engineering Education Training Mode Reform Pilot. contents of stamping basic principle, stamping process design and calculation, typical structure and design method of stamping die which need to be mastered by students after finishing the course; another objective of "capacity" refers to design capacity stamping die with medium complexity, problem-solving skills in stamping production, and the preliminary capacity of researching and developing new process and technology, all of which should be mastered by students after learning and practice teaching.

The first level, theory teaching is the main of the course, which should be mastered by students; the second level, case teaching is mainly based on typical cases in order to enhance theory content and form a clear knowledge frame; the third level, extracurricular self-learning mainly aims to consolidate knowledge and master stamping die design material, expand the area of knowledge. The three levels are not independent each other, but also interrelated, as well as intercross in teaching process, so as to achieve the goal both of knowledge and ability.

Furthermore, with consideration of demand for talents and major construction based on depth fusion in local economic, many content have been increased in the course, including multi position progressive die, car overlays die and other advanced stamping process and die. While the traditional course mainly includes three basic stamping process of blanking, bending and drawing, as well as brief introduction of flanging and bulging, necking, rectification and spinning as self-study content[1].

\section{Teaching MAterial CONSTRUCtion}

At present, there are many materials for the course, most of which are old in content, do not keep up with the pace of technological innovation, lack of necessary design case in teaching process of point -by-point [2].

In order to meet better the requirements of teaching objectives and talent training, the new version textbook of "stamping process and die design" has been completed by 
teachers of Anhui Engineering University, which used the lasted stamping standards and specification and focused on combination with actual production, fully embodied the base and advancement of stamping theory (increasing multi position progressive die, car overlays die, precision blanking die, $\mathrm{CNC}$ stamping and other advanced stamping process content). At the same time, the textbook is shown in lively form, each chapter of which has " capability requirement " and "extended reading" to introduce extracurricular reading can enrich extracurricular knowledge , expand students' horizons and improve students' interest in learning and self-learning ability. The textbook conforms to the requirement of "knowledge plus capability"[1].

Based on the background of project-oriented teaching reform, according to teaching objectives, Jilin Technology College of Electronic Information has completed a projectoriented textbook of "stamping process and die" in cooperation with enterprise which broken the traditional teaching system, , introduced typical stamping case from enterprises according to the corresponding professional jobs and typical working task, put forward the project-oriented textbook mode integrated of "teaching, learning, doing", and had good effect. The content of the teaching material was designed according to occupation and task, of which the project module was based on typical stamping cases of enterprises. Each project had the flow of "goal, task plan, knowledge link, project implementation, project development and practice" according to the process of the case. And some relevant information required to complete the case had been provided in the appendix of the textbook [3].

\section{Teaching Mode AND Method}

\section{A. Project-Oriented Teaching}

Based on teaching task and training goal of the course "stamping process and die design", Shanghai Dianji University made new attempt and further exploration combining with teaching practices. According to the actual condition of "technology undergraduate students", project-oriented teaching mode has been introduced with changing of traditional teaching mode, with comprehensive application of heuristic education and discussion-based teaching. And combined with a variety of teaching methods, it improved students' learning interest, increased teaching effect. The implementation process of the method is shown in "Fig. 1".

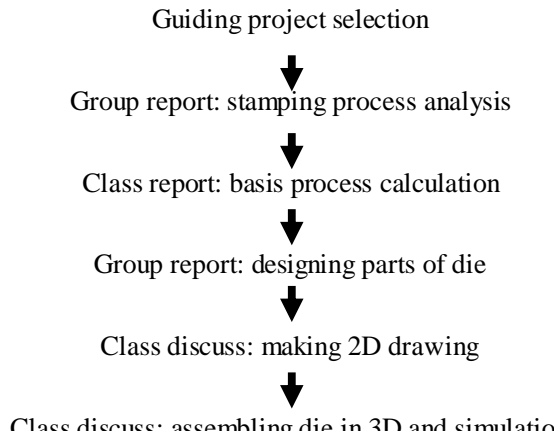

Fig. 1. The process of project-oriented teaching
At the time of the first class, a number of die design cases with moderate difficulty are issued; some groups are constructed with a number of students each of which has a group leader who takes charge of holding a project seminar, in the end to help teachers give score of each team member, included in the total score according to a certain proportion. As shown in Fig.1, the entire process includes five times concentration seminar including two seminars within group and three comprehensive seminars which are participated in by teachers who will give stage design results. [4]

\section{B. Integration of Theory and Practice}

Wuhan Software Engineering College took application of integration of theory and practice as shown in Fig.2 which should be supported by hardware and software including hardware such as laboratory, training room and practice base of university-industry cooperation, and software such as teaching materials of integration of theory and practice and teacher guide. Currently Wuhan Software Engineering has established a stamping die assemble workshop, stamping workshop, CAD / CAM training room, and hired experienced engineers from production line in cooperation with teachers to guide students in practical training and curriculum design, which laid the foundation of integration of theory and practice teaching mode[5].

\section{Modular Teaching Mode}

The module teaching mode has been adopted in Guangdong Industrial and Commercial High School, including five parts of course teaching, project training, die disassembling, assembling and mapping, die manufacturing and post practice, with teaching process designed on base of stamping process analysis and actual working process of die design including die structure design, equipment selection and die manufacturing. [6]

\section{Teaching Mode of Five-In-One}

The teaching mode of Five-in-One has been adopted in Bengbu College which is made of teaching theory, animation teaching, experiment teaching, on-the-spot teaching, and production process. In the theory teaching, grasp the key problems, and teach clearly from outside to inside, from shallow to deep, and layer upon layer, so as to draw the conclusion. When teaching, teachers made use of an animation to show which can transfer complex and abstract static problems into an image of dynamic teaching, as well as attract students' attention and improve receptivity and master ability of students. At the same time, cognition and debugging experiment of punch press, stamping die cognition and testing experiment, assembly and disassembly experiment of common stamping die have been carried out by students. On-the-spot teaching is mainly applied to forming law, principle, mechanism and components and so on, and has multiplier effect. Finally, using spare time, students make dies, so as to improve their design ability and practical operation ability [7].

\section{E. Research-Oriented Teaching Mode}

Under the guidance of teachers, students actively acquire knowledge, apply knowledge and solve problems [8]. 
The structure of bending die and drawing die is simple, but the process is complex. Based on study of die structure and working principle, research-oriented teaching mode has been applied in Heilongjiang Bayi Agricultural University to present special research tasks and let students find information by Internet or library to solve problems [9].

\section{Multimedia ResourCe CONSTRUCTION AND INFORMATION-BASED TEACHING}

3D assembly drawings, exploded drawings, 2D die assembly drawings and main parts drawings have been drawn with Pro / E in Jiyuan Vocational and Technology College who has built a 2D drawing and a 3D model of 16 stamping parts, and 16 design specifications in form of e-document which can be used in task driven teaching of "stamping process and die design", also can be used as teaching content or practice object of "mechanical drawing and AutoCAD" and "PRO/E application foundation" [10].

Information-based teaching has been used in Hengyang Finance and Economics Vocational Technical Institute, using animation, production videos etc. to teach. Additionally, students have been guided to find favorable learning resources from Internet, so as to cultivate learning ability by using Internet. The learning problems can be solved by teachers through QQ, e-mail, We-Chat and other ways which are no longer limited by time and space of classroom.

Yantai Automotive Engineering Vocational Technical Institute mainly built databases of die animation resources, design resources and questions bank, has completed 3D animation of die selected by the course, and collected and finished stamping process foundation materials, common parts standards of cold stamping die and parts of cold stamping die standards. In construction of questions bank, according to teaching focus and difficulty, set up corresponding training questions. Ten typical cases of stamping die with whole process of design have been selected, so as to be easy selfstudy and self-examination. [12].

\section{CONCLUSION}

In the course of "stamping process and die design", in order to achieve better teaching effect, many colleges have done a lot of work in aspects of teaching content, teaching material construction, teaching mode, teaching method and multimedia resources construction etc.. It is found that project - oriented mode and integration mode of theory and practice are the tendency of the reform, as well as the most effective teaching modes.

\section{REFERENCES}

[1] Xing Chang, Miao Guobing. Exploration and Practice of "Stamping Process and Die Design" Course Teaching Reform [J]. Science and Technology Innovation Herald, 2013, (4): 193-193.

[2] Dou Xiaoli stamping Teaching Reform [J]. China Science and Technology Information, 2012 (23): 165.

[3] Xiao Yahui. Development of Teaching Materials of "Stamping Process and Die Design" Project in Higher Vocational School [J]. Henan Science and Technology, 2014,20: 251-252.
[4] Wang Xiaomei. Apprlication of Teaching Methods of "Stamping Process and Die Design" Project[J]. Science and Technology Innovation Herald, 2014, (12): 122-122.

[5] Xiao Zhiyu, Ye Zhijuan[1]. Development and Practice of Theory and Practice Integrated Mode Teaching of "Stamping Process and Die Design" Curriculum[J]. Vocational Education of Machinery, 2014, (7): 39-41.

[6] Huang Yuexun, Zheng Pingping, Chen Guangyao. Reform of "Cold Stamping Process and Die Design" Teaching [A]. Papers of Outstanding Achievements Awards 2013 in Scientific Research by Chinese Vocational Association (Vol. 2) [C ]: 2013: 10.

[7] Meng Pu, Gan Ruixia. Discussion on Cold Stamping Process And Die Design Teaching based on Application[J] .Chinese Education Technology And Equipment, 2015,20: 92-93.

[8] Zhang Yin. Researchers - Learners: the Construction of Researchoriented Learning Curriculum and Teaching System [J]. Liaoning Education Research, 2004, (7): 63-65.

[9] Dai Hongqing, Zhang Fugang, Jin Zhongbo, Han Xia, Hu Chunying, Huang Wenyi. Exploration of Research-oriented Teaching in "Stamping Process and Die Design" Course[J].China Electric Power Education, 2014,08.: 100-101.

[10] Zhao Huijuan, Liu Bo, Li Xiufu et al. Research and Development of Multimedia Resources in "Stamping Process and Die Design"[J]. Journal of Jiyuan Vocational and Technical College, 2015,14 (3): 93-96.

[11] Lu Yuansan [1]. Informationlized Teaching Design of "Stamping Process and Die Design" Course[J]. Die Manufacturing, 2014, (1): 9294.

[12] Cao Wei. Thinking and Practice of Enterprises to Participate in "Stamping Process and Die Design" Course Construction [J]. Vocational Technology, 2013,10: 27. 